\title{
XF-ROVIM, un robot para la detección de enfermedades en campo mediante teledetección. Aplicación a la detección de Xylella fastidiosa
}

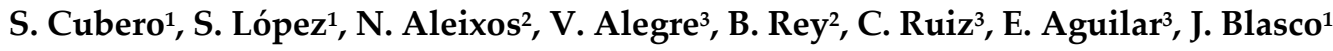 \\ 1 Centro de Agroingeniería. Instituto Valenciano de Investigaciones Agrarias (IVIA). CV-315, km 10,7 - \\ 46113 Moncada (Valencia), España; cubero_ser@gva.es \\ 2 Departamento de Ingeniería Gráfica. Universitat Politècnica de València (UPV). Camino de Vera, s/n, \\ 46022 Valencia, España. \\ 3 TRAGSA. CV-315, km 10,7 - 46113 Moncada (Valencia), España.
}

\begin{abstract}
Resumen: Se ha desarrollado un robot flexible y económico, fácil de transportar y capaz de embarcar equipos de teledetección, con el objetivo de inspeccionar cultivos arbóreos en el marco del proyecto H2020 XF-ACTORS, financiado por la UE (\#727987). El robot XF-ROVIM se maneja por control remoto y se impulsa gracias a dos motores eléctricos. Permite equipar dos cámaras réflex (una modificada para imágenes BNDVI), una cámara multiespectral (ocho bandas entre 550 y $850 \mathrm{~nm}$ ), una cámara hiperespectral de barrido (rango 400 - $1000 \mathrm{~nm}$ ) y una cámara térmica. Además, se ha montado un escáner LiDAR 2D para obtener características estructurales tridimensionales de los árboles, un receptor GNSS para geolocalizar las imágenes y datos obtenidos, y una unidad de medida inercial (IMU) para corregir los datos capturados por el LiDAR influenciados por las irregularidades del terreno.Se ha utilizado para detectar olivos infectados por Xylella fastidiosa mediante teledetección en una parcela potencialmente afectada en la región de Lecce (sur de Italia). El robot recorrió el cultivo monitorizando las cuatro caras de cada árbol (más de 400 árboles) con cámaras (más de 35000 imágenes) y la información LiDAR. Los datos ya analizados se pueden visualizar sobreimpresos en el mismo campo utilizando la aplicación Google Earth®.
\end{abstract}

Palabras clave: visión por computador, imagen espectral, agricultura de precisión, LiDAR

\section{Introducción}

Xylella fastidiosa (Xf) es una peligrosa bacteria que llegó hace relativamente poco tiempo a Italia donde ha causado daños muy graves y enormes pérdidas en los cultivos de olivos [1]. Posteri0ormente se ha extendido por el sur de Francia y Córcega y más recientemente se ha detectado en Mallorca, Alicante y Madrid en España [2]. Por ello, Xf se está convirtiendo en una amenaza para toda Europa y las medidas preventivas contra esta enfermedad se están fortaleciendo mediante la implementación, entre otras medidas, de programas de vigilancia y contención impulsadas por la UE.

Para diagnosticar correctamente los cultivos afectados, es necesario realizar un muestreo adecuado. Por ejemplo, en árboles infectados, el análisis de solo unas pocas hojas puede devolver un diagnóstico negativo si el muestreo no se realiza adecuadamente. Además, para conocer la gravedad del problema, es necesario hacer muestreos de grandes extensiones, a nivel de parcela o incluso de región, con una alta resolución, lo que implica un coste elevado que en la mayoría de los casos puede ser inviable. 


\section{CONGRESO IBÉRICO DE AGROINGENIERÍA \\ X CONGRESSO IBÉRICO DE AGROENGENHARIA \\ 3 - 6 septiembre 2019, Huesca - España}

Una alternativa complementaria a los sistemas de muestreo tradicionales a pie de campo, es el uso de sensores remotos capaces de detectar problemas en los cultivos y mapear la distribución de la enfermedad. Estos sensores han evolucionado considerablemente durante las últimas décadas y actualmente permiten realizar muestreos a diferentes escalas, dependiendo del área que se va a monitorear, así como de la resolución espacial y espectral requerida [3]. Para grandes extensiones, se pueden utilizan imágenes de satélite que ofrecen altas resoluciones espectrales, pero con una resolución espacial relativamente escasa. Hoy en día, la reducción de precios y la miniaturización de los equipos hacen que los sistemas aéreos no tripulados (UAV) sean cada vez más populares para monitorizar áreas con resoluciones más altas, ofreciendo información espectral en el momento que se precise y en relativamente poco tiempo. Sin embargo, la autonomía y el radio de acción de estos equipos de estos equipos es todavía pequeño y su uso limitado para realizar campañas de vigilancia a nivel regional. Una alternativa reside en el uso de avionetas tripuladas, que permiten cubrir grandes extensiones [4]. Sin embargo, a veces es necesario realizar observaciones a nivel de campo para obtener información de las plantas individuales a una resolución muy alta. Para obtener esta información se utilizan dispositivos manuales o sensores montados en vehículos agrícolas, ya sean estándar como tractores o desarrollados a medida para cada caso.

Este trabajo presenta el desarrollo de un robot de campo, XF-ROVIM [5], que incorpora equipos para el sensado remoto. Este robot se está utilizando para la detección temprana de $\mathrm{Xf}$ y se ha probado en campos de olivos potencialmente infectados por $X f$ en la región de Apulia (Italia). Los datos del cultivo recolectados en el campo están bajo estudio, por lo que en este trabajo se presenta únicamente el desarrollo del robot, sus equipos y sus componentes y los ensayos realizados.

\section{Materiales y métodos}

Se ha diseñado y construido un pequeño vehículo eléctrico terrestre que permite embarcar un conjunto de sensores para monitorizar cultivos arbóreos (Figura 1). El vehículo tiene unas dimensiones de $100 \times 60 \mathrm{~cm}$, lo que permite que sea fácilmente transportable en el interior de una furgoneta. Además de los sensores, el vehículo alberga en su interior dos baterías de gel fácilmente reemplazables que dotan de autonomía a todo el sistema. También en su interior se encuentra un ordenador industrial, una pantalla de visualización que puede abatirse y quedar oculta durante los ensayos con el vehículo y toda la electrónica y cableado desarrollado a medida para controlar el movimiento del vehículo, la sincronización de los equipos y la alimentación de los sensores.

El vehículo se conduce a través de un mando a distancia remoto y tiene una autonomía real de unas 6-8 horas de funcionamiento ininterrumpido a pleno rendimiento. Debido a la gran altura de los árboles en los campos de ensayo (unos $6 \mathrm{~m}$ ), las cámaras se han colocado en una plataforma que se puede elevar hasta $3 \mathrm{~m}$ sobre el nivel del suelo, de forma que una imagen pueda abarcar toda la copa del árbol. Para sincronizar la adquisición de datos con el avance del vehículo y para alimentar todos los sensores, se ha desarrollado una placa electrónica que recibe los pulsos de dos codificadores ópticos situados en los ejes de los motores de tracción, generados según avanza el vehículo. De este modo, las imágenes se puedan adquirir a distancias establecidas de avance configurables desde el mando remoto, con el objetivo de conseguir imágenes del campo con el menor solapamiento posible. La información proporcionada por los codificadores ópticos también se utiliza para la gestión del movimiento del vehículo debido a la integración de un controlador proporcional, integral y derivativo (PID) que actúa sobre los motores de tracción, permitiendo un funcionamiento manual a través de un mando joystick o un funcionamiento automático a velocidad constante prefijada desde el propio mando.

El conjunto de sensores montados en el vehículo terrestre está formado por dos cámaras réflex, una Canon EOS 600D (Canon Inc, Japón) estándar y otra Canon EOS 550D (Canon Inc, 


\section{CONGRESO IBÉRICO DE AGROINGENIERÍA \\ X CONGRESSO IBÉRICO DE AGROENGENHARIA \\ 3- 6 septiembre 2019, Huesca - España}

Japón) modificada para obtener imágenes BNDVI (Índice de Vegetación de Diferencia Normalizada en el azul), una cámara multiespectral Silios CMS-V (Silios Technologies, Peynier, Francia), un sistema hiperespectral de barrido en el rango entre 400 y $1000 \mathrm{~nm}$ compuesto por un espectrógrafo (Imspector V10, Specim Spectral Imaging Ltd., Oulu, Finlandia) y una cámara (Eye5220CP, iDS Imaging Development Systems GmbH, Obersulm, Alemania) y una cámara térmica (A320, FLIR Systems, Wilsonville, OR, EE.UU.).

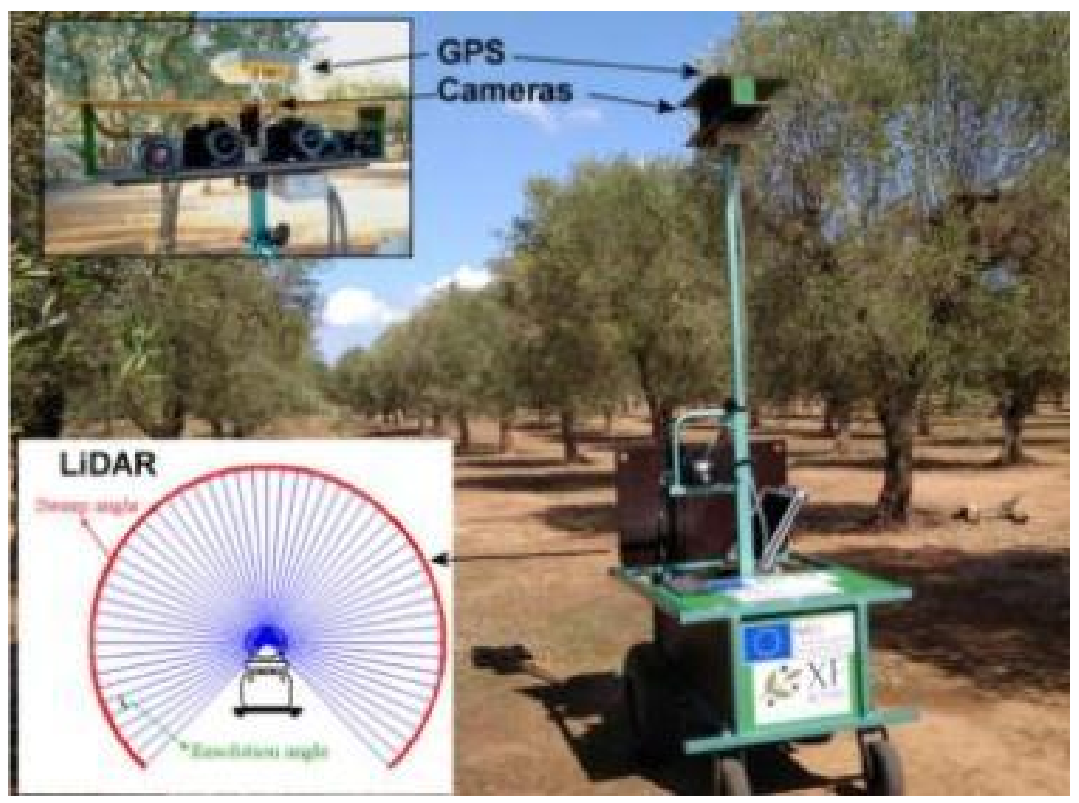

Figura 1. XF-ROVIM, conjunto de sensores y rango LiDAR

Las cámaras réflex tienen sensores de 18 megapíxeles y lentes EF-S de $10 \mathrm{~mm}$ que pueden ofrecer imágenes con una resolución de $0,5 \mathrm{~mm} /$ píxel. El rango de la cámara multiespectral está entre 550 y $830 \mathrm{~nm}$ y puede obtener imágenes en 8 longitudes de onda diferentes $(558,589,623$, 656, 699, 732, 769 y $801 \mathrm{~nm}$ ). Esta cámara tiene un tamaño de sensor de 1280 x 1024 píxeles y monta una lente de $6 \mathrm{~mm}$ que ofrece una resolución de $2,5 \mathrm{~mm}$ por píxel. Utilizando las bandas 656 y 801 obtenidas por esta cámara, se ha calculado el índice NDVI (Índice de Vegetación de Diferencia Normalizada). Estas cámaras están configuradas para tomar imágenes sincronizadas con el avance del vehículo, con un intervalo de aproximadamente una imagen por metro, utilizando tiempos de integración de menos de $4 \mathrm{~ms}$ para evitar imágenes en movimiento o borrosas.

La cámara hiperespectral proporciona una resolución efectiva de 1288 píxeles espaciales por 1028 bandas espectrales en todo el rango espectral (400 - $1000 \mathrm{~nm})$ que corresponden a una única línea vertical, por lo que es necesario sincronizar la adquisición con el movimiento del vehículo para unir todas las líneas formando las imágenes hiperespectrales de los árboles. La resolución espectral del sistema es de $9 \mathrm{~nm}$ y el tiempo de integración de $4 \mathrm{~ms}$. Por su parte, la cámara termográfica proporciona imágenes térmicas con una resolución de 320×240 píxeles, aunque para esta aplicación en movimiento, dado que la frecuencia de adquisición de la cámara utilizada no es muy alta, no han resultado útiles.

Además, el robot incorpora un sensor LiDAR (LMS 111, Sick AG, Reute, Alemania), un receptor GNSS (Hiper SR, Topcon Positioning Group, Tokyo, Japón) y un sensor de medición inercial (IMU) de 9 ejes (BNO055, Bosch Sensortech GmbH, Reutlingen, Alemania) para la geolocalización y corrección de la información escaneada con el LiDAR provocada por las irregularidades del terreno. Estos tres dispositivos se configuraron para muestrear a una frecuencia de $25 \mathrm{~Hz}$. La sincronización entre los datos proporcionados por estos tres equipos y del 


\section{CONGRESO IBÉRICO DE AGROINGENIERÍA \\ X CONGRESSO IBÉRICO DE AGROENGENHARIA \\ 3- 6 septiembre 2019, Huesca - España}

sistema de geolocalización con las imágenes se realiza utilizando un código de hora (con resolución de ms) en la que se adquiere cada dato y se almacenan en un archivo para cada fila escaneada.

Las coordenadas LiDAR (originalmente en $\mathrm{mm}$ ) se han corregido utilizando los datos de la IMU como son los ángulos de inclinación y giro. Posteriormente, se geolocalizaron los puntos utilizando los datos proporcionados por el receptor GNSS que cuenta con corrección en tiempo real (RTK) y una precisión en torno a $3 \mathrm{~cm}$, y se transforman en coordenadas UTM (m). En la Figura 2 se muestra la información proporcionada por el LiDAR en tiempo real de uno de los árboles mientras el vehículo (cuadrado rojo a la derecha) se desplaza en la dirección de la flecha. Uniendo la información de las cuatro caras escaneadas de cada árbol, es posible crear una imagen reconstruida del mismo en 3D. Todo el software se ha desarrollado en MATLAB (Mathworks, Natick, Massachusetts, EE.UU.).

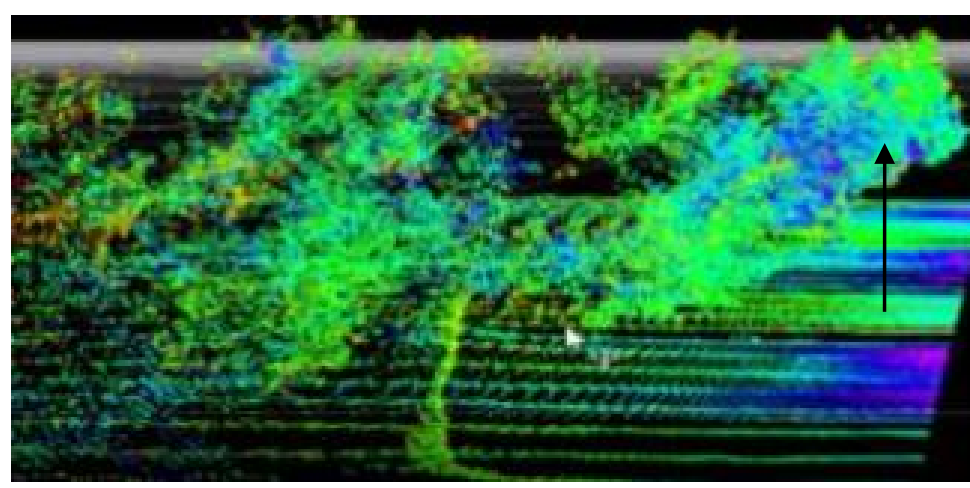

Figura 2. Información on-line proporcionada por el LiDAR

Los ensayos se han realizado en un campo de olivos a disposición del proyecto en la región de Lecce, Apulia (Italia) (Figura 3a). El campo tenía un total de 430 árboles cuyos síntomas visuales fueron anotados de forma individual para cada una de las caras de cada árbol, con un nivel de severidad entre 0 (sin síntomas) y 4 (árbol desecado). Para monitorizar todo el campo, el vehículo siguió un recorrido en dirección norte-sur desde el punto de origen, monitorizando los olivos en el lado izquierdo según avanza el vehículo, para posteriormente hacer el recorrido en sentido contrario y escanear el árbol del otro lado de la fila, como muestran las flechas en la Figura $3 b$. Una vez terminado el recorrido en dirección norte-sur, se procede a realizar del mismo modo el recorrido en direcciones oeste-este, logrando monitorizar las cuatro caras de cada árbol.
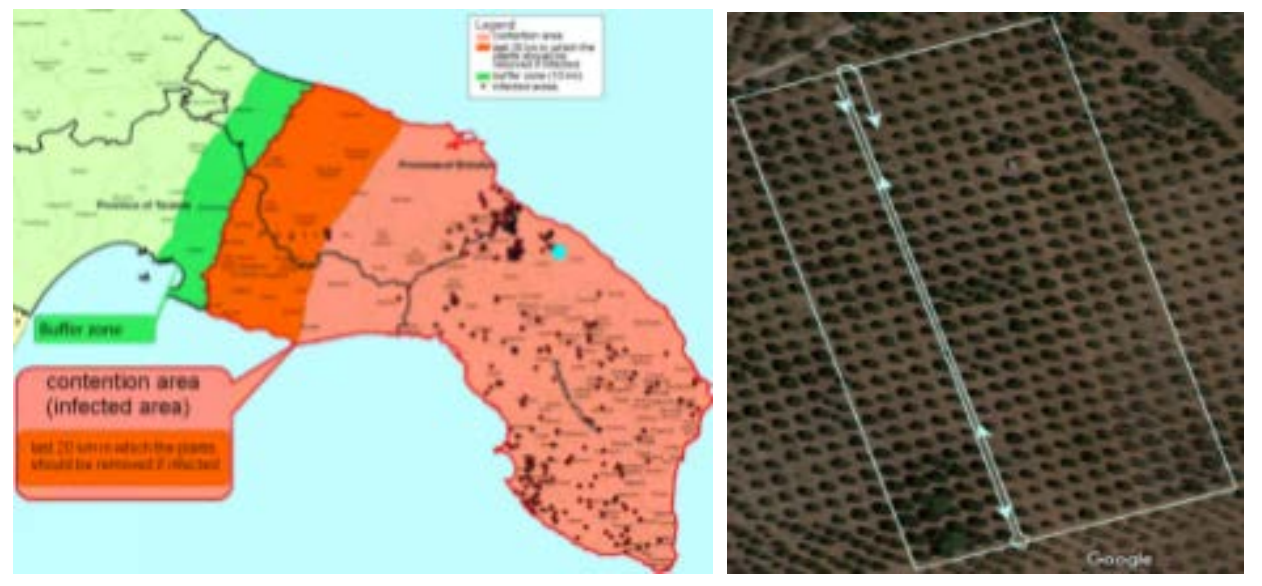

Figura 3. a) Zona infectada en Apulia (Italia); b) Parcela de ensayos en Lecce (Italia) 
Después de la reconstrucción 3D, los puntos de cada árbol en el campo se proyectan en la zona UTM como una vista superior del campo. Luego, se extrajo el contorno (calculado como un área convexa) de la vista superior de cada árbol, que se utiliza para calcular el índice de área foliar (LAI), la densidad foliar (LAD) y el índice de vegetación de diferencia normalizada (NDVI).

\section{Resultados y discusión}

XF-ROVIM funcionó correctamente durante las pruebas en un campo de olivos relativamente altos, siendo capaz de inspeccionar todo el campo sin interrupciones mientras capturaba datos válidos. En cada ensayo se capturaron alrededor de 35000 imágenes con las cinco cámaras. La unidad de conducción remota resultó ser una herramienta flexible y fácil de usar para mover el robot por todo el campo. Se realizaron algunas pruebas de manejo, que mostraron la posibilidad de rodear cada árbol para una inspección individualizada completa. Sin embargo, se tomó la decisión de inspeccionar filas enteras. Como el control remoto podía programarse para mantener la velocidad y la dirección una vez establecido, no se necesitaba ninguna intervención durante la inspección de las filas. Las baterías duraron más de seis horas de funcionamiento continuo y podrían cambiarse por otro juego en menos de 15 minutos.

Visualmente, la mayoría de los árboles no mostraban síntomas de la enfermedad, probablemente debido al proceso de limpieza llevado a cabo por el propietario, pero algunos otros árboles mostraban síntomas leves a moderados. En total, 174 árboles mostraron algún síntoma, principalmente aquellos en los lados oeste y norte. Los datos recolectados por los sensores se encuentran bajo estudio. Sin embargo, los primeros resultados del análisis automatizado de los índices NDVI y BNDVI de los árboles de las imágenes capturadas (Figura 4) lograron un coeficiente de determinación $R^{2}$ en relación con los síntomas observados inferiores a 0,45 en ambos casos, lo que indica que estos índices no son adecuados para este problema. Además, como se ha demostrado en [3], otros índices vegetativos relacionados con diferentes pigmentos que involucran longitudes de onda en el rango VIS / NIR (400-1000 nm) pueden ofrecer resultados más prometedores en la detección de la infección por Xf en olivos.
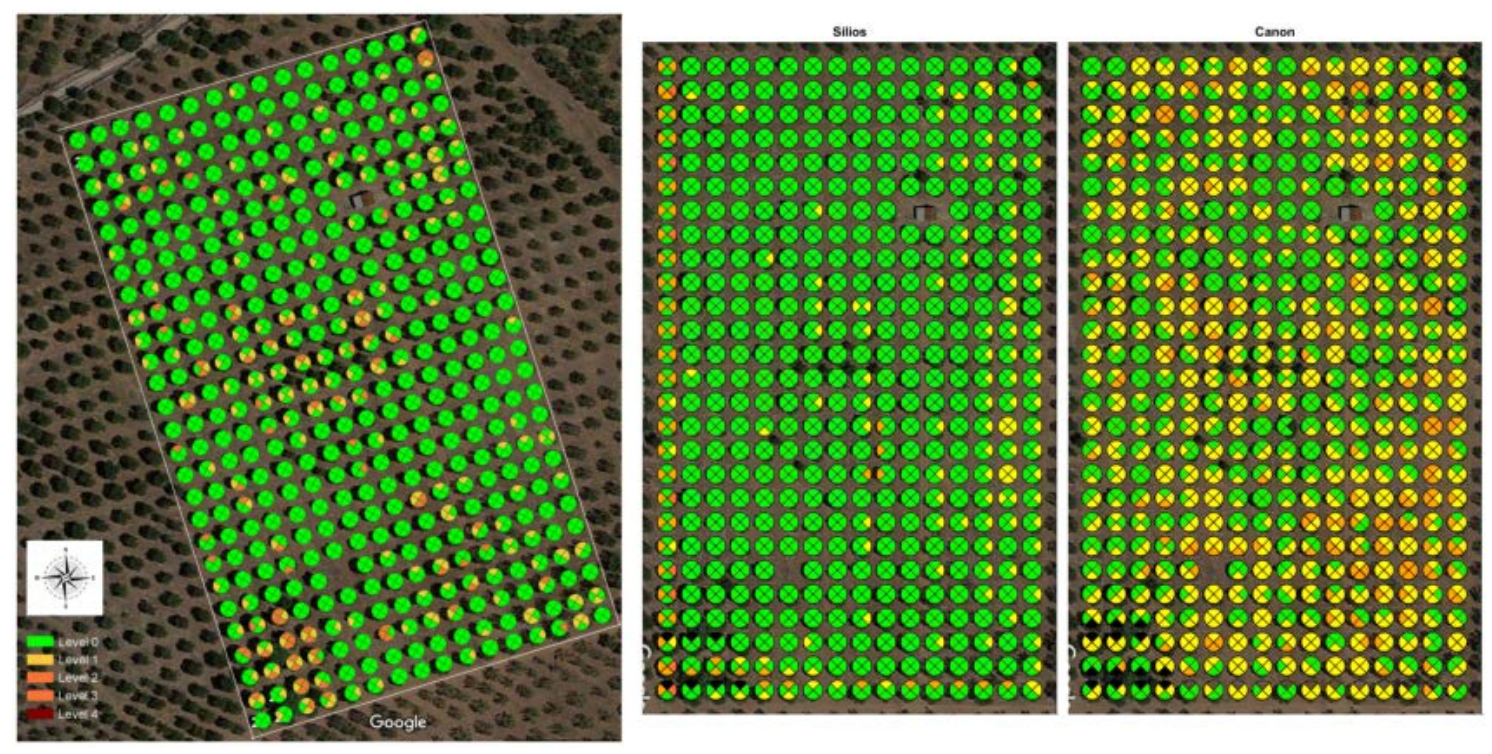

Figura 4. Severidad observada visualmente en el campo (izquierda), y predicha por los índices BNDVI (centro) y NDVI (derecha) 


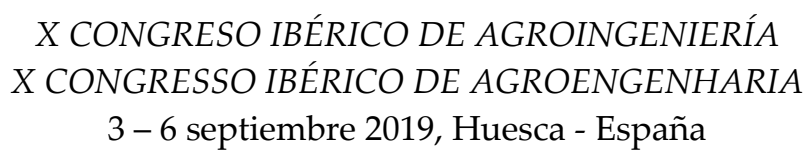

\section{Conclusiones}

XF-ROVIM ha demostrado ser una herramienta flexible, económica, fácil de transportar y capaz de transportar equipos de detección remota o proximal para la inspección de cultivos de árboles. Puede inspeccionar un campo de 4 ha sin interrupciones en menos de seis horas, lo que permite la captura y almacenamiento de datos de campo de alta resolución que se geolocalizan y sincronizan con su avance.

Se ha diseñado un sistema de control remoto para conducirlo a través del campo, lo que permite que la velocidad y la dirección se preajusten automáticamente. Permite la instalación de diferentes cámaras de color, térmicas, multiespectrales e hiperespectrales, así como un escáner LiDAR y un dispositivo de geolocalización para georreferenciar todos los datos adquiridos. El diseño permite elevar las cámaras hasta $300 \mathrm{~cm}$ para adaptarlas a la altura de diferentes árboles. El sistema se ha probado en un campo de olivos potencialmente infectados por Xf ubicado en un área de Italia. Las primeras pruebas de campo se realizaron satisfactoriamente y tanto el robot como el equipo funcionaron correctamente sin ningún problema durante las pruebas. Los datos adquiridos han permitido que las imágenes de todos los árboles en el campo se recopilen en los cuatro lados, además de la creación de mapas de campo que muestran la estructura 3D de los árboles, así como diferentes índices vegetativos.

\section{Agradecimientos}

Este trabajo se ha financiado parcialmente por la UE a través del proyecto H2020 № 727987 Xylella Fastidiosa Active Containment Through a Multidisciplinary-Oriented Research Strategy (XF-ACTORS).

\section{Referencias}

1. Martinelli F., Scalenghe R., Davino S., Panno S., Scuderi G., Ruisi P., Villa P., Stroppiana D., Boschetti M., Goulart LR., Davis CE., Dandekar AM. Advanced methods of plant disease detection. A review. Agronomy for Sustainable Development. 2015, 35 (1-25)

2. Olmo, D.; Nieto, A.; Adrover, F.; Urbano, A.; Beidas, O.; Juan, A.; Marco-Noales, E.; López, M. M.; Montes Borrego, Miguel; Navas Cortés, Juan Antonio; Landa, Blanca B. First Detection of Xylella fastidiosa Infecting Cherry (Prunus avium) and Polygala myrtifolia Plants, in Mallorca Island, Spain, Plant Disease 2017, 101, 1820. DOI: 10.1094/PDIS-04-17-0590-PDN

3. Vicent, A.; Blasco, J. When prevention fails. Towards more efficient strategies for plant disease eradication. New Phytologist, 2017, 214, 905-908.

4. Zarco-Tejada, P.J.; Camino, C.; Beck, P.S.A.; Calderon, R.; Hornero, A.; Hernández-Clemente, R.; Kattenborn, T.; Montes-Borrego, M.; Susca, L.; Morelli, M.; Gonzalez-Dugo, V.; North, P.R.J.; Landa, B.B.; Boscia, D.; Saponari, M.; Navas-Cortes, J.A. Pre-visual symptoms of Xylella fastidiosa infection revealed in spectral plant-trait alterations, Nature Plants, 2018, 4,432-439

5. Rey B, Aleixos N, Cubero S, Blasco J (2019) XF-ROVIM. A field robot to detect olive trees infected by Xylella fastidiosa using proximal sensing. Remote Sensing. Special Issue Advances in Remote Sensing Applications for the Detection of Biological Invasions, 11(3), 221. DOI: 10.3390/rs11030221. Open Access. 